\title{
Participation of Lectin in Biological Effects of Raw Winged Bean Seeds on Rats
}

\author{
Masako Higuchi, Masako Suga and Kazuo IwaI \\ Department of Food Science and Technology, Faculty of Agriculture, \\ Kyoto University, Sakyo-ku, Kyoto 606, Japan \\ Received February 28, 1983
}

\begin{abstract}
The biological effects of raw winged bean seeds were investigated with feeding experiments on rats, and the effects of lectin (phytohemagglutinin) present in the seeds are discussed. Administration of a $30 \%$ raw winged bean diet caused strong growth depression in young rats, and led to death within 10 20 days, inducing severe damage to the small intestine of the rats. Significant morphological changes of the intestinal mucosa were observed with a microscopic investigation. As the lethal effect was eliminated by autoclaving but not removed with supplementation of $0.5 \% \mathrm{~L}$-methionine to the raw winged bean diet, the lectin was assumed to be closely related to the deleterious effects of raw winged bean. In vitro and in vivo digestion tests of the lectin revealed that the winged bean lectin had resistance to peptic, pancreatic and membrane digestions. The hemagglutinating activity was also detected in the intestinal mucosa and faeces from rats ingesting the raw winged bean or its purified lectin. The binding action of lection to mucosal epitheliums of the gastrointestinal tract is suggested to be the initial step of the deleterious effects induced by the winged bean lectin.
\end{abstract}

Ripe seeds of winged bean (Psophocarpus tetragonolobus (L.) DC) have been brought attention in recent years as constituting a promising legume in the tropics due to its agricultural and nutritional potential. ${ }^{1 \sim 3)}$ Concerning the nutritional value of winged bean, we have previously indicated that winged bean had favorable quality as one of the food resources from the point of view of its proximate composition and the fatty acid composition in its oil. ${ }^{4)}$ The biological effects of raw winged bean on rats were first reported by Jaffé $e t$ al., i.e., the raw winged bean were toxic and caused pancreatic hypertrophy and spleen atrophy. ${ }^{5)}$ The occurrence and some properties of the antinutritional factors such as protease inhibitors and lectin (phytohemagglutinin) in raw winged bean have been reported. 6,7) However, the toxic of the winged bean lectin to animals have not yet been investigated.

Lectin, having the ability to agglutinate the red blood cells of various species of animals has been recognized to be present in many legume seeds. ${ }^{8)}$ It is also presumed to be related to the raw bean's adverse effects which can be lethal. However, not all lectins are toxic to animals. Their toxicity is also dependent on the animal species ${ }^{8}$ and different according to the way in which the lectin was formed.

The present paper describes the participation of lectin in the biological effects of raw winged bean seeds on rats.

\section{MATERIALS AND METHODS}

Materials. Ripe seeds of winged bean (Psophocarpus tetragonolobus (L.) DC) were obtained from Malaysia. The seeds were ground into a fine meal with a Retsch cyclone mill. The seeds contained $32.2 \%$ of protein, $21.2 \%$ of carbohydrate, $20.3 \%$ of fat, $13.8 \%$ of fiber and $4.0 \%$ of ash as has been previously reported. ${ }^{4)}$

Chemicals. Soybean lectin (Type VI) was obtained from Sigma Chemical Co., $p$-aminophenyl- $\beta$-D-galactopyranoside was purchased from Koch-Light Laboratories Ltd., and CNBr-activated Sepharose 4B was obtained from Pharmacia Fine Chemicals. All other chemicals of analytical grade were purchased from commercial sources. 
Amino acid analysis. Winged bean seed meal was hydrolyzed with $6 \mathrm{~N} \mathrm{HCl}$ at $110^{\circ} \mathrm{C}$ for $24 \mathrm{hr},{ }^{9)}$ and the amino acids, except for tryptophan, in the hydrolysate were determined using a Hitachi 835 high performance amino acid analyzer equipped with a data processor. Cystine in the seed meal was oxidized with performic acid ${ }^{10)}$ before hydrolysis with $6 \mathrm{~N} \mathrm{HCl}$. Tryptophan was determined with the $p$-dimethylaminobenzaldehyde method described by Spies and Chambers. ${ }^{11)}$

Hemagglutinating activity. Hemagglutination tests were carried out with 2-fold serial dilution of the samples ${ }^{12)}$ on microtiter plates. Trypsin-treated rabbit red blood cells were used at $4 \%(\mathrm{v} / \mathrm{v})$ and the agglutination was determined after incubation at $37^{\circ} \mathrm{C}$ for $1 \mathrm{hr}$.

Animal feeding experiments. Albino male rats of the Wistar strain were housed singly in metabolic cages in an environmentally-controlled room at $22^{\circ} \mathrm{C}$ with a $12 \mathrm{hr}$ light/dark cycle. The composition of the diets is shown in Table I. Casein serving as the control contained no lectin and trypsin inhibitor. These experimental diets contained approximately $10 \%$ of protein. Nitrogen balance experiment for raw winged bean was carried out by dividing the experimental period into two parts. In the first week, rats were fed on a no-protein diet which contained carbohydrate in place of protein, and in the second week rats were equally divided into two groups, i.e., the raw winged bean diet group and the casein diet group. The diets and water were fed ad libitum, and the rats were weighed at 10:00 a.m. every day. In each period, faeces and urine were collected for the last 3 days. Nitrogen in the faeces and the urine was determined by the micro Kjeldahl method. ${ }^{13)}$

Purification of lectin from raw winged bean seeds. Extracts with $6 \mathrm{~mm}$ phosphate-buffered saline ( $\mathrm{pH}$ 7.2) from defatted raw winged bean meal agglutinated rabbit red blood cells, and the agglutinating activity was specifically inhibited by D-galactose. Based on this observation, winged bean lectin was purified with an affinity column of $p$-aminophenyl- $\beta$-D-galactopyranoside-bound Sepharose 4B after ammonium sulfate fractionation (precipitated between $35 \%$ and $75 \%$ saturation) and gel filtration on Sephadex G-100. The lectin obtained after elution with $0.5 \mathrm{M}$ lactose in the phosphate-buffered saline from an affinity column and following dialysis was indicated to be electrophoretically homogeneous. The purified lectin contained $15.8 \%$ of nitrogen.

In vitro and mucosal digestion tests of winged bean and soybean lectins. The tests were performed with the purified winged bean lectin in comparison with the soybean lectin. Pepsin digestion was carried out by incubating with shaking about $1 \mathrm{mg}$ of these lectins with $4 \mathrm{mg}$ of pepsin in $15 \mathrm{ml}$ of $0.1 \mathrm{~N} \mathrm{HCl}$. Pepsin-pancreatin digestion was performed by adding $4 \mathrm{mg}$ of pancreatin in $7.5 \mathrm{ml}$ of $\mathrm{pH} 8.0$
TABle I. COMPOSITION OF EXPERIMENTAL DiETS

\begin{tabular}{|c|c|c|c|}
\hline \multirow{2}{*}{ Ingredients } & \multicolumn{3}{|c|}{$\begin{array}{l}\text { Diet designation } \\
\text { ( } g / 100 \mathrm{~g} \text { of diet) }\end{array}$} \\
\hline & Casein & Winged bean & Soybean \\
\hline \multicolumn{4}{|l|}{ Protein } \\
\hline Casein & 11 & - & - \\
\hline Raw winged bean & 一 & 30 & - \\
\hline Soybean flake ${ }^{a}$ & - & - & 20 \\
\hline Corn starch & 59 & - & 52 \\
\hline Sucrose & 15 & 65 & 15 \\
\hline Soybean oil & 8 & - & 8 \\
\hline Mineral mixture $^{b}$ & 4 & 4 & 4 \\
\hline Vitamin mixture $^{c}$ & 1 & 1 & 1 \\
\hline Cellulose powder & 2 & - & - \\
\hline
\end{tabular}

${ }^{a}$ Obtained from Honen Seiyu Co., Inc.

${ }^{b}$ Obtained from Oriental Yeast Co., Inc. Composition (mg/kg of diet): $\mathrm{CaHPO}_{4} \cdot 2 \mathrm{H}_{2} \mathrm{O}$, 582.4; $\mathrm{KH}_{2} \mathrm{PO}_{4}, 1028.8 ; \mathrm{NaH}_{2} \mathrm{PO}_{4}, 37.4 ; \mathrm{NaCl}$, 186.4; Ca-lactate, 1403.6; Fe-citrate, 127.2; $\mathrm{MgSO}_{4}$, 286.8; $\quad \mathrm{ZnCO}_{3}, \quad 4.4 ; \quad \mathrm{MnSO}_{4} \cdot 4 \sim 6 \mathrm{H}_{2} \mathrm{O}, \quad 4.8$; $\mathrm{CuSO}_{4} \cdot 5 \mathrm{H}_{2} \mathrm{O}, 1.2 ; \mathrm{KI}, 0.4$.

c Obtained from Oriental Yeast Co., Inc. Composition $(\mathrm{mg} / \mathrm{kg}$ of diet): thiamine $\cdot \mathrm{HCl}, 12$; riboflavin, 40; pyridoxine $\cdot \mathrm{HCl}, 8$; cyanocobalamin, 0.005 ; ascorbic acid, 300; biotin, 0.2; folic acid, 2; calcium pantothenate, $50 ; \rho$-aminobenzoic acid, 50 ; niacin, 60; inositol, 60; choline chloride, 2000; retinyl acetate, 1.72; cholecalciferol, $0.025 ; \alpha$-tocopheryl acetate, 50; menadione, 52; cellulose, 7312 .

phosphate buffer after 2-hr peptic digestion and neutralization with $0.2 \mathrm{~N} \mathrm{NaOH}^{14)}$ After a 2-hr incubation of each lectin with pancreatin, the brush border membranes isolated from rat small intestine ${ }^{15)}$ were added as the enzyme source. All the digestion mixtures were incubated at $37^{\circ} \mathrm{C}$, and, at each incubating period, the hemagglutinating activity was measured. The digestibility of lectin was expressed by the ratio of the remaining activity at each period to the initial activity.

In vivo digestion test of winged bean lectin. Rats weighing about $200 \mathrm{~g}$ were force-fed with the test meal after an 8-hr fast. The composition of the test meal was as follows: Purified winged bean lectin, $4 \mathrm{mg}$; egg albumin, $250 \mathrm{mg}$; soluble starch, $600 \mathrm{mg}$; sucrose, $275 \mathrm{mg}$; soybean oil, $0.075 \mathrm{ml}$; mineral mixture, $48 \mathrm{mg}$; phenol red saturated solution, $2.0 \mathrm{ml}$. The composition of mineral mixture is shown in Table I. Control rats were force-fed with the diet in which the lectin had been omitted. The rats were sacrificed by decapitation at certain planned time intervals, the abdominal cavity was opened, and ligatures were quickly placed at the pylorus, ileocecal junction, gastroesophageal junction and rectosigmoid. The small intestine was divided into three equal segments, namely 
the proximal, middle and distal regions. The contents of these segments, caecum and colon were collected by washing each lumen with $0.05 \mathrm{M}$ phosphate buffer $(\mathrm{pH} 7.2)$ containing $0.002 \%$ of $p$-tosyl-L-lysine chloromethyl ketone and $p$-tosyl-L-phenylalanine chloromethyl ketone, inhibitors of trypsin and chymotrypsin, respectively; the contents of the stomach were collected by washing with cold saline. Lectin bound to the intestinal mucosa was detected by determining its activity in the supernatant after liberation of the lectin with $0.5 \mathrm{~m}$ lactose in the phosphatebuffered saline. The hemagglutinating activity in faeces was measured after extraction with the phosphatebuffered saline. Digestibility was expressed by the ratio of remaining hemagglutinating activity to the initial activity of liquid meal before its administration to rats.

Light microscopy. Rats fed on the raw winged bean diet or the casein diet were sacrificed by decapitation and segments of the small intestine next to the pylorus were quickly removed. For light microscopy, paraffin sections were prepared after fixation in $10 \%$ formalin and stained with hematoxylin-eosin. Cross-sections were examined with a Nikon OPTIPHOT microscope, and were photographed with a Nikon UFX-35A.

\section{RESULTS}

\section{Amino acid composition of winged bean}

The amino acid composition of winged bean is shown in Table II. Its essential amino acid pattern is very close to that of soybean, while the contents of lysine and tyrosine are higher than in soybean. When compared with the FAO/WHO provisional pattern, ${ }^{16)}$ the sulfurcontaining amino acids were demonstrated to be a limiting amino acid, giving an amino acid score of 77 .

\section{Feeding experiments with raw winged bean}

The results of nitrogen balance experiments using rats fed on the $30 \%$ raw winged bean diet are given in Table III. The raw winged bean group showed that apparent loss of nitrogen through the faeces was 3.5-fold that of the casein group, whereas their food intake was only approximately half of those in the casein group. Concerning the excretion of nitrogen in the urine, there was no significant difference between the raw winged bean group and the casein group. After correcting these values by the endogenous losses of nitrogen, which were
Table II. Amino Acid Composition of Winged BEAN SEEDS

Amino acids, except for tryptophan, were analyzed with a Hitachi 835 high performance amino acid analyzer, and tryptophan was determined with the $p$ dimethylaminobenzaldehyde method. Experimental details are given in Materials AND Methods.

\begin{tabular}{lc}
\hline Amino acid & $\mathrm{g}$ amino acid $/ 16.0 \mathrm{~g} \mathrm{~N}$ \\
\hline Tryptophan & 1.8 \\
Lysine & 7.5 \\
Histidine & 2.6 \\
Arginine & 6.6 \\
Aspartic acid & 11.1 \\
Threonine & 4.9 \\
Serine & 6.0 \\
Glutamic acid & 14.0 \\
Proline & 5.3 \\
Glycine & 4.2 \\
Alanine & 4.1 \\
Cystine & 1.7 \\
Valine & 4.7 \\
Methionine & 1.0 \\
Isoleucine & 4.0 \\
Leucine & 8.1 \\
Tyrosine & 4.9 \\
Phenylalanine & 4.6
\end{tabular}

Table III. Results of Nitrogen Balance Experiments Obtained with Rats Fed on Raw Winged Bean Diet and Casein Diet

\begin{tabular}{lcc}
\hline & $\begin{array}{c}\text { Raw winged } \\
\text { bean }\end{array}$ & Casein \\
& $116 \pm 4$ & $124 \pm 2$ \\
& $-2.2 \pm 0.2$ & $4.0 \pm 0.4$ \\
Initial body weight (g) & & \\
Daily weight gain (g) & & \\
Intakes for 3 days (g) & $21.2 \pm 2.5$ & $47.7 \pm 0.4$ \\
$\quad$ Food & $0.38 \pm 0.05$ & $0.72 \pm 0.02$ \\
$\quad$ Nitrogen & & \\
$N$-Excretion for 3 days (g) & & \\
Protein diet & $0.22 \pm 0.05$ & $0.06 \pm 0.01$ \\
$\quad$ Faeces & $0.15 \pm 0.05$ & $0.19 \pm 0.03$ \\
$\quad$ Urine & & \\
Non-protein diet & $0.03 \pm 0.01$ & $0.04 \pm 0.01$ \\
$\quad$ Faeces & $0.08 \pm 0.01$ & $0.09 \pm 0.03$ \\
$\quad$ Urine & $49 \pm 5$ & $97 \pm 2$ \\
Digestibility (\%) & $57 \pm 8$ & $85 \pm 5$ \\
Biological value (BV) & & \\
Net protein utilization & $28 \pm 7$ & $83 \pm 5$ \\
$\quad$ (NPU) & & \\
\end{tabular}

Values are the mean \pm SD for 6 rats.

obtained from the results of non-protein feeding, the true digestibility and biological value ${ }^{17)}$ of winged bean were calculated on average 


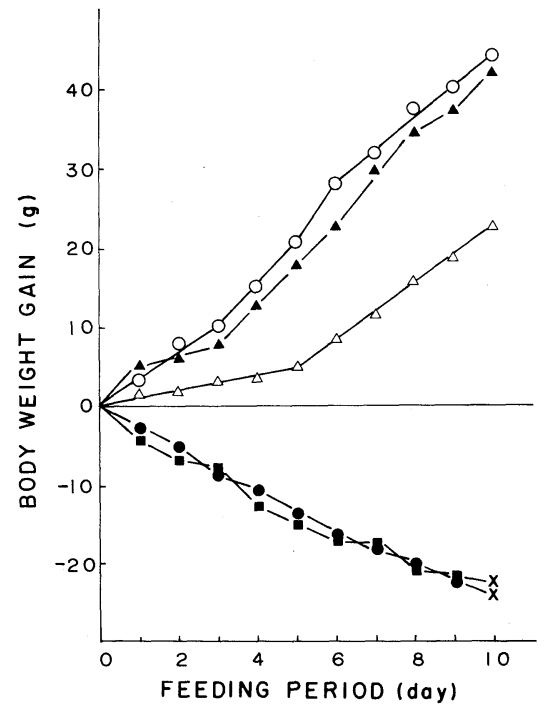

FIG. 1. Changes in Body Weight of Rats Fed on a $10 \%$ Protein Diet.

$\bigcirc$, casein diet; $\bigcirc$, raw winged bean diet; $\triangle$, raw soybean diet; $\boldsymbol{\Delta}$, autoclaved winged bean diet; $\boldsymbol{\square}$, raw winged bean supplemented with $0.5 \%$ L-methionine diet.

to be $49 \%$ and 57 , respectively. These values are very low as compared with other legume seeds and suggest the poor suitability of raw winged bean for animals.

Figure 1 shows the results of comparative growth experiments with winged bean and soybean on rats weighing 90 to $100 \mathrm{~g}$; the raw winged bean diet caused a continuous decrease in body weight ( $2 \sim 3 \mathrm{~g}$ per day) and all the rats died within $10 \sim 20$ days, while the raw soybean diet only caused a growth retardation. The antinutritional effects of raw winged bean was demonstrated to be much greater than those of raw soybean. When winged bean was autoclaved at $120^{\circ} \mathrm{C}$ for $30 \mathrm{~min}$, body weight gains of the rats were comparable to those from the casein diet. This result suggests that the lethal action is fully eliminated by autoclaving. On the other hand, the deleterious effect of the raw winged bean diet on rats was not removed by feeding a diet supplemented with $0.5 \% \mathrm{~L}$-methionine. In all rats continuously ingesting only the raw winged bean diet, significant hemagglutinating activities were detected in their faeces. However, no type of diarrhea was observed throughout all the feeding periods. Figure 2 shows micrographs of the small intestine taken from one of the rats fed on the raw winged bean diet for 12 days. In these rats a much lower villus height of the small intestine, as well as irregular forms and arrangements of the microvilli, were observed in comparison with those in the rats fed on the casein diet. A significant atrophy of the spleen was also observed in rats ingesting the raw winged bean diet.

\section{In vitro digestion of the purified winged bean lectin}

A comparison of in vitro digestibilities of the purified winged bean lectin and the soybean lectin is shown in Fig. 3. The winged bean lectin fully maintained its activity during a 5-hr incubation with pepsin at $\mathrm{pH} 1.8$ and a 24-hr incubation with pancreatin at $\mathrm{pH} 8.0$, whereas the activity of the soybean lectin was reduced to about $25 \%$ of its initial activity by a $2-\mathrm{hr}$ incubation with pepsin or pancreatin.

\section{Mucosal digestion of the purified winged bean lectin}

As given in Fig. 4, the winged bean lectin had a resistance to enzymic digestion with the brush border membrane. On the other hand, the activity of the soybean lectin was reduced to about $25 \%$ of its initial activity by incubating with the brush border membrane.

\section{In vivo digestion of the purified winged bean lectin}

Figure 5 shows the distribution of hemagglutinating activity throughout the gastrointestinal tract at progressive time intervals after administration of the purified winged bean lectin to rats. The movement of the lectin in the gastrointestinal tract was similar to the meal flow estimated by the content of phenol red used as a nonabsorbable marker. The phenol red content was determined by the difference of absorbance at 520, 560 and $600 \mathrm{~nm}$ at $\mathrm{pH} 9.2 .^{18)}$ Strong hemagglutinating activity was detected in the stomach $(46 \%)$ and middle region of the small intestine $(42 \%)$ at 

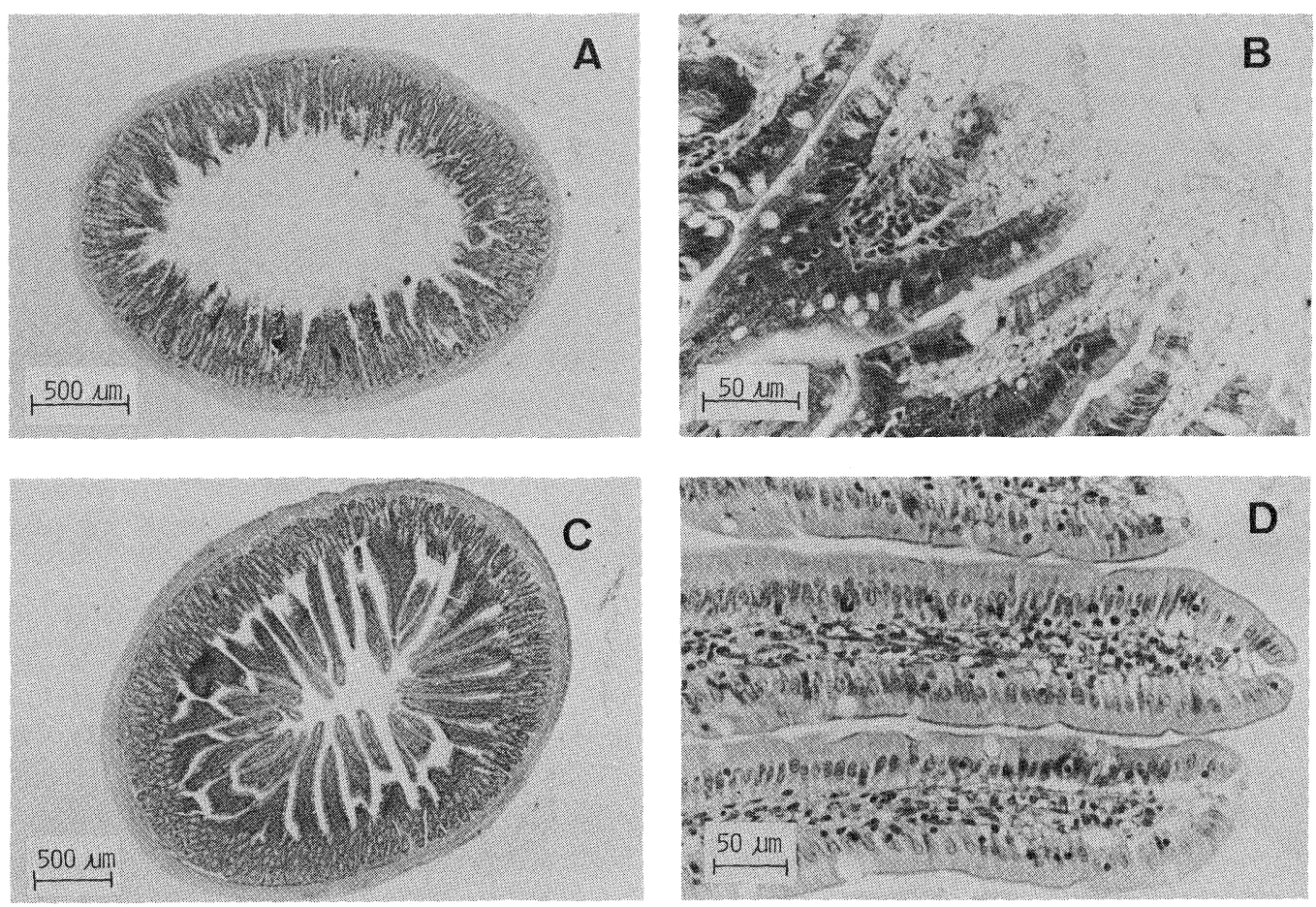

FIG. 2. Micrographs of the Cross Sections of the Small Intestine Taken from a Rat Fed on the Raw Winged Bean Diet or the Casein Diet.

(A): Cross section of the small intestine from a rat fed on the raw winged bean diet for 12 days, showing the decrease in villus height $(\mathrm{H} \& \mathrm{E}, \times 10)$.

(B): Higher magnification of Fig. 2A, showing morphological abnormalities of the villi (H \& E, $\times 100)$.

(C): Cross section of the small intestine from a rat fed on the casein diet for 12 days $(\mathrm{H} \& \mathrm{E}, \times 10)$.

(D): Higher magnification of Fig. 2C, showing normal villus morphology. (H \& E, × 100).

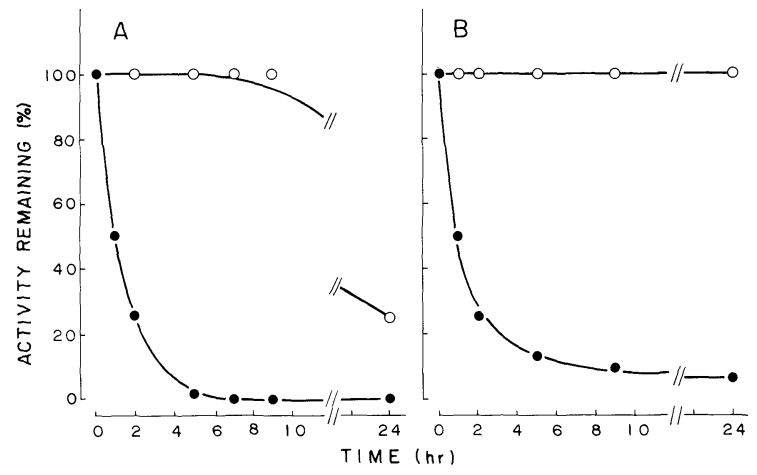

FIG. 3. In Vitro Digestion of the Purified Winged Bean Lectin ( $\bigcirc)$ and the Soybean Lectin (O).

Pepsin digestion (A) was carried out by incubating the lectin with pepsin ( $\mathrm{pH} \mathrm{1.8)}$ at $37^{\circ} \mathrm{C}$. Pepsin-pancreatin digestion (B) was performed by adding pancreatin $(\mathrm{pH} \mathrm{8.0)}$ after a 2-hr peptic digestion and neutralization. Hemagglutinating activity in the digestive mixture was determined at each incubating period, and the digestibility of lectin was expressed by the ratio of the remaining activity in each period to its initial value. Experimental details are shown in MATERIALS AND METHODS. 
$30 \mathrm{~min}$ after the administration, and furthermore, in both the middle $(33 \%)$ and the distal region $(44 \%)$ at $60 \mathrm{~min}$. At these time intervals, the hemagglutinating activity was also detected at approximately 1 to $5 \%$ level in the supernatant of the intestinal mucosa. The strongest activity was detected at $3 \mathrm{hr}$ in the caecum $(73 \%)$, and at $21 \mathrm{hr}$ in the faeces $(40 \%)$. The hemagglutinating activity in the supernatant of the intestinal mucosa completely disappeared at $21 \mathrm{hr}$.

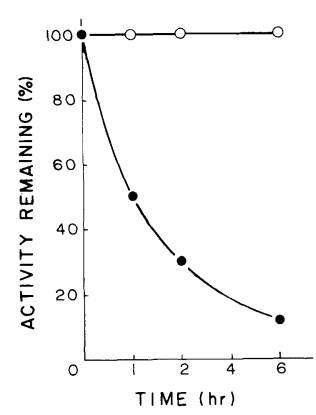

Fig. 4. Mucosal Digestion of the Purified Winged Bean Lectin $(\bigcirc)$ and the Soybean Lectin

Brush border membrane isolated from the rat small intestine was added to the digestive mixture after a $2-\mathrm{hr}$ peptic and pancreatic digestion. Digestibility of the lectin was expressed by ratio of remaining hemagglutinating activity in each period to its initial value. Experimental details are given in MATERIALS AND Methods.

\section{DISCUSSION}

The amino acid composition of winged bean showed that most of the essential amino acids were contained in adequate levels except for sulfur-containing amino acids (Table II). From an analysis of different varieties of winged bean, Okezie et ll $^{3)}$ have reported results similar to our study. They demonstrated that contents of lysine and tryptophan were higher than these in most other oil seeds, and the sulfur-containing amino acids were the limiting amino acids, giving an amino acid score of 74 on average.

Feeding experiments on rats indicated that the administration of raw winged bean could not support the growth of rats, but rather led to death within a short period (Fig. 1). These results are not inconsistent with the recent paper reported by Jaffé et al. ${ }^{5}$ in which the body weight of rats ingesting the raw winged bean diet decreased every day and all these rats died within 15 days. Another effect observed in the raw winged bean group was the significant depression of appetite of the rats. Since the deleterious effects were fully eliminated by autoclaving, the toxic factors are suggested to be heat-labile. The fact that a diet supplemented with $0.5 \% \mathrm{~L}$-methionine failed to prevent

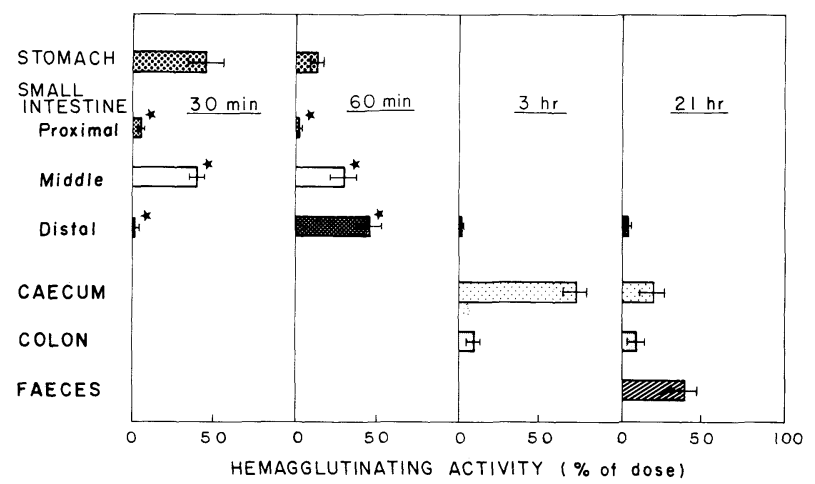

FIG. 5. In Vivo Digestion of the Purified Winged Bean Lectin.

Hemagglutinating activity in each of the luminal contents, intestinal mucosa and faeces was determined at various time intervals after administration of the liquid meal containing the purified winged bean lectin. Digestibility was expressed by ratio of remaining hemagglutinating activity to the initial activity of the liquid meal before its administration to rats. The region of the small intestine marked with a star $(*)$ contains the activity due to lectin bound to the intestinal mucosa. Experimental details are given in MATERIALS AND Methods. 
this growth depression suggests that trypsin inhibitor would not be responsible for the lethal action of raw winged bean. In the case of soybean trypsin inhibitor, the addition of $\mathrm{L}$ methionine to the raw soybean diet improved protein utilization to the same extent as autoclaving. ${ }^{19)}$ Amylase inhibitor also seems to be unrelated to the lethal effect, because surcrose was used as the sole source of carbohydrate in the raw winged bean diet. From these results, lectin can be assumed to be the main lethal constituent in winged bean. This assumption is also supported by a microscopic observation. The small intestine of rats ingesting raw winged bean for 12 days showed morphological abnormalities and shortening of the villi in the intestinal mucosa (Fig. 2). This observation agrees with the results previously made with rats fed on lectin purified from kindney beans (Phaseolus vulgaris). ${ }^{20)}$ Recently Kimura et al. have reported significant reductions in hydrolase activities localized in the brush border membrane of the small intestine of rats ingesting a $30 \%$ raw winged bean diet for 4 days, while they did not observe any apparent disorder in the gastrointestinal tract. ${ }^{21)}$

Lectin isolated from winged bean was revealed to have resistance to peptic, pancreatic and mucosal digestions (Figs. 3 and 4), whereas the soybean lectin was rapidly inactivated by these digestions. This is an interesting characteristic of the winged bean lectin from a nutritional standpoint. The difference in toxicity between the winged bean lectin and the soybean lectin, when these lectins are orally administered to rats, can be explained by the different susceptibility to the digestive enzymes.

The results of in vitro and in vivo digestion tests (Figs. $3 \sim 5$ ) suggest that the winged bean lectin could not be inactivated by passage through the gastrointestinal tract, and that it would bind to the intestinal mucosa during passing through the small intestine, and the rest would be excreted into faeces in a form still capable of agglutinating red blood cells. The binding of lectin to the epithelial cells of the intestinal mucosa would be an initial step in the deleterious effects induced by the winged bean lectin.

It has been reported that the epithelial cells covering the villi of the intestine, proliferating in the crypt at the base of the villi, move up the villi while undergoing morphological and functional changes, and matured cells are finally extruded from the tips of the villi. ${ }^{22,23)}$ In rats ingesting raw winged bean, a significant decrease in the villus height and abnormality in the microvilli was observed (Fig. 2). These observations suggest that the powerful binding action of lectin to the epithelial cells may cause an increasing cell loss from the villi. The small intestine with abnormal villi may have only a very poor ability of digestion and/or absorption, and would consequently induce a nonspecific interference to the hydrolysis and absorption of nutrients. These phenomena would lead to the accelerated death of the recipient animals.

Acknowledgments. We are grateful to Dr. S. Takaori and Dr. M. Sasa, Department of Pharmacology, Faculty of Medicine, Kyoto University, for their assistance and suggestions in microscopic research. We also thank Ms. H. Okuda, Department of Ophthalmology, Faculty of Medicine, Kyoto University, for preparing the samples for the microscopic investigation, and Mr. H. Kobayashi, President of K. Kobayashi \& Co., Ltd., for providing winged bean.

\section{REFERENCES}

1) K. Cerny, M. Kordylas, F. Pospisil, O. Svabensky and B. Zajic, Br. J. Nutr., 26, 293 (1971).

2) F. Pospisil, S. K. Karikari and E. Boaman-mensah, World Crops, September/October, 1971, p. 260.

3) B. O. Okezie and F. W. Martin, J. Food Sci., 45, 1045 (1980).

4) M. Higuchi, J. Terao and K. Iwai, J. Nutr. Sci. Vitaminol., 28, 511 (1982).

5) W. G. Jaffé and R. Korte, Nutr. Report Inter., 14, 449 (1976).

6) A. A. Kortt, Biochim. Biophys. Acta, 577, 371 (1979).

7) S. G. Pueppke, Biochim. Biophys. Acta, 581, 63 (1979).

8) W. G. Jaffé, "Toxic Constituents of Plant Foodstuffs," ed. by I. E. Liener, Academic Press Inc., New York, N. Y., 1980, p. 82.

9) D. H. Spackman, W. H. Stein and S. Moore, Anal. Chem., 30, 1190 (1958).

10) S. Moore, J. Biol. Chem., 238, 235 (1963). 
11) J. R. Spies and D. C. Chambers, Anal. Chem., 20, 30 (1948); 21, 1249 (1949).

12) T. K. Gartner, J. M. Gerrard, J. G. White and D. C. Williams, Nature, 289, 688 (1981).

13) J. M. Concon and D. Soltess, Anal. Biochem., 53, 35 (1973).

14) W. R. Akeson and M. A. Stahmann, J. Nutr., 83, 257 (1964).

15) M. Fujita, H. Matsui, K. Nagano and M. Nakao, Biochim. Biophys. Acta, 233, 404 (1971).

16) Report of a Joint FAO/WHO Ad Hoc Expert Committee, "Energy and Protein Requirements," World Health Organization, Geneve, 1973.

17) H. H. Mitchell, J. Biol. Chem., 58, 873 (1923 1924).
18) H. P. Schedle and J. A. Clifton, Gastroenterol., 41, 491 (1966).

19) I. E. Liener and M. L. Kakade, "Toxic Constituents of Plant Foodstuff," ed. by I. E. Liener, Academic Press Inc., New York, N. Y., 1980, p. 40.

20) T. P. King, A. Pusztai and E. M. W. Clarke, J. Comp. Path., 90, 585 (1980).

21) T. Kimura, C. Satanachote and A. Yoshida, J. Nutr. Sci. Vitaminol., 28, 27 (1982).

22) B. Messier and C. P. Leblond, Am. J. Anat., 106, 247 (1960).

23) H. L. Webster and O. D. Harrison, Exp. Cell Res., 56, 245 (1969). 